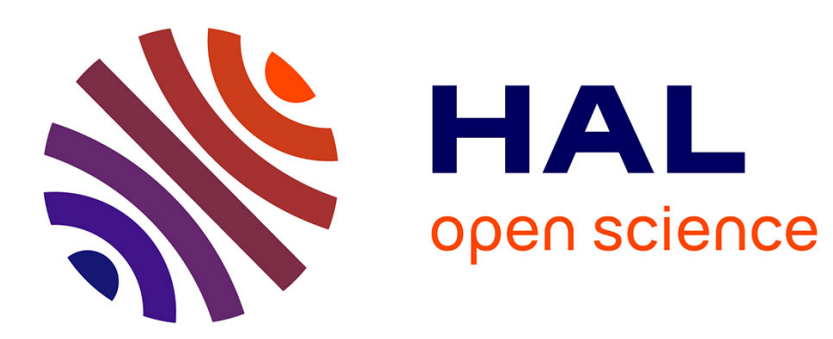

\title{
The effect of different methods of cross-linking of collagen on its dielectric properties
}

\author{
E. Marzec, K. Pietrucha
}

\section{To cite this version:}

E. Marzec, K. Pietrucha. The effect of different methods of cross-linking of collagen on its dielectric properties. Biophysical Chemistry, 2007, 132 (2-3), pp.89. 10.1016/j.bpc.2007.10.012 . hal-00501689

\section{HAL Id: hal-00501689 \\ https://hal.science/hal-00501689}

Submitted on 12 Jul 2010

HAL is a multi-disciplinary open access archive for the deposit and dissemination of scientific research documents, whether they are published or not. The documents may come from teaching and research institutions in France or abroad, or from public or private research centers.
L'archive ouverte pluridisciplinaire HAL, est destinée au dépôt et à la diffusion de documents scientifiques de niveau recherche, publiés ou non, émanant des établissements d'enseignement et de recherche français ou étrangers, des laboratoires publics ou privés. 


\section{Accepted Manuscript}

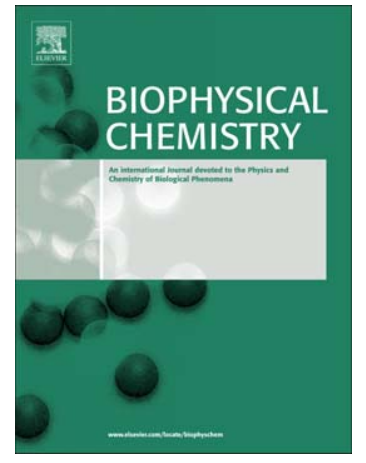

The effect of different methods of cross-linking of collagen on its dielectric properties

E. Marzec, K. Pietrucha

PII: $\quad$ S0301-4622(07)00255-4

DOI: $\quad$ doi: $10.1016 /$ j.bpc.2007.10.012

Reference: $\quad$ BIOCHE 5037

To appear in: Biophysical Chemistry

Received date: $\quad 28$ April 2007

Revised date: $\quad 20$ October 2007

Accepted date: 22 October 2007

Please cite this article as: E. Marzec, K. Pietrucha, The effect of different methods of cross-linking of collagen on its dielectric properties, Biophysical Chemistry (2007), doi: 10.1016/j.bpc.2007.10.012

This is a PDF file of an unedited manuscript that has been accepted for publication. As a service to our customers we are providing this early version of the manuscript. The manuscript will undergo copyediting, typesetting, and review of the resulting proof before it is published in its final form. Please note that during the production process errors may be discovered which could affect the content, and all legal disclaimers that apply to the journal pertain. 


\title{
The effect of different methods of cross-linking of collagen on its dielectric properties
}

\author{
E. Marzec ${ }^{*}$, K. Pietrucha \\ *Department of Biophysics, Poznań University of Medical Sciences, Fredry 10, 61-701 \\ Poznań, Poland \\ Institute of Architecture of Textiles, Technical University of Łódź, ul. S. Żeromskiego 116, \\ 90-924 Łódź, Poland
}

\begin{abstract}
This paper reports on the effect of different methods of collagen cross-linking on its dielectric properties. In order to obtain collagen-hyaluronic acid (HA) scaffolds, collagen was first dehydrated by a combination of thermal and vacuum drying (DHT) and then treated with the chemical reagent carbodiimide (EDC/NHS) for final cross-linking. The measurements of the relative permittivity $\varepsilon^{\prime}$ and the dielectric loss $\varepsilon$ " for all materials were carried over the frequency range of $10 \mathrm{~Hz}-100 \mathrm{kHz}$ and at temperatures from 22 to $260^{\circ} \mathrm{C}$. The results for these samples reveal distinct relaxation processes at low temperatures, below $140^{\circ} \mathrm{C}$ and at higher temperatures as broad peak around $230^{\circ} \mathrm{C}$. The first and second relaxation are associated with changes in the secondary structure of collagen accompanied by the release of water and with the denaturation of dry collagen, respectively. The influence of cross-linking on the permittivity of collagen is significant over the entire temperature range.
\end{abstract}

Keywords: collagen; dielectric properties; cross-linking; denaturation; relaxation.

"Corresponding author:

Ewa Marzec, Department of Biophysics, Poznań University of Medical Sciences, Fredry 10, 61-701 Poznań, Poland

ewaklcde@amu.edu.pl

tel.: +480618546227 


\section{Introduction}

One of the applications of biomedical materials is for construction of devices that can replace defective tissues or organs. Recently much improvement in the design and production of biomedical devices has been made [1-3]. The current research is directed towards engineering of tissue with specific surface configurations, surface chemical modifications, pharmacologicaly active surfaces, biological integration, and/or resorbable scaffolds, depending on the biomedical requirements [4-7]. Collagen and HA, important components of extracellular matrix (ECM), have been used as a viscoelastic biomaterial for different medical purposes (bone or soft connective tissue implants, prostheses for nerve regeneration, artificial skin, wound dressing and so on) as well as scaffolds for tissue engineering [8-12]. Our interest in the preparation and characterization of the collagen modified with hyaluronic acid originates from its unique properties as matrix in the field of tissue engineering. In this field the biocompatible, biodegradable materials are used as a support matrix or as a substrate for the delivery of cultured cells or for three-dimensional tissue reconstruction [13-15]. It is also known that cell behaviour like migration, proliferation and differentiation may be mediated by physico-chemical properties of the matrices $[16,17]$. The biodegradation rate of collagen based materials, including collagen-HA scaffolds, is known to be strongly affected by the cross-linking density [6-8]. Numerous papers have appeared on the collagen-HA systems concerning mainly the biological, structural and thermo-mechanical analysis of these materials. The experimental methods used to recognise the effect of chemical cross-linking on the physicochemical properties of collagen also include dielectric spectroscopy techniques [18-21]. Recently, the dielectric spectroscopy has permitted in vitro measurements of the dielectric properties of human and animal tissues [30]. In addition, in vivo all the physiological processes are accompanied by the flow of electric current through such structural elements as intra- and extracellular fluids and charge accumulation at the interface, for example of collagen and water in the bone or tendon. These conduction and polarization mechanisms in the tissues are possible thanks to their dielectric properties. So, in the tissue engineering the dielectric properties of biomaterials should be similar to or even better than those of the regenerating tissues and organs.

In this paper, particular attention has been paid to the influence of different methods of collagen cross-linking on its dielectric relaxation behaviour. In addition, we analysed the effect of water on the dielectric properties of materials studied. The interaction of waterunmodified collagen in the solid state has been extensively studied by many authors $[18,32-$ 40]. The data obtained concerned the classification of water associated with collagen into 
categories, the methods of water elimination from collagen even up to $0 \%$ water concentration and also the function of water in stabilizing the triple-helical structure of collagen. In vivo this protein occurs in the solid state but only in the restricted temperature range, and therefore, many works $[19,20,31-33,38,41-45]$ have been devoted physical properties of collagen above physiological temperature. The temperature ranges corresponding to the decomposition of water and collagen have been established.

The results of this work are extension of our earlier dielectric studies of dry unmodified and chondroitin sulfate (CS)- and hyaluronic acid (HA)- modified collagen [21].

\section{Experimental procedures}

\subsection{Materials}

Type I collagen was isolated and purified from porcine Achilles tendon using pepsin digestions, specific salt precipitation and acetic acid dissolution [22].The method includes the following operations: swelling of mechanically disintegrated tendons in $10 \% \mathrm{NaCl}$, homogenisation of a previously washed material with water and filtration. From the supernatant, collagen was precipitated by adding $0.1 M \mathrm{Na}_{2} \mathrm{HPO}_{4}$. The precipitate was then suspended in $0.1 \mathrm{M} \mathrm{HCl}$ with the addition of $0.5 \%$ pepsin. Afterwards collagen was precipitated by means of $0.02 \mathrm{MNa}_{2} \mathrm{HPO}_{4}$, filtered off, washed with distilled water and finally dissolved in $0.1 \mathrm{M} \mathrm{CH}_{3} \mathrm{COOH}$. The analysis of amino-acid composition (analyzer Jeol ILC -3 BC2) and IR spectroscopy (BIO-RAD FTS 175C) confirmed a very high purity of the prepared system. The collagen solution was characterized by molecular weight, $\mathrm{M}_{\mathrm{v}}=3.9 \mathrm{x}$ $10^{5}$, denaturation temperature, $\mathrm{T}_{\mathrm{d}}=38.8^{\circ} \mathrm{C}$ and $\mathrm{pH}=3.5$.

Hyaluronic acid (HA), 1-ethyl-3-(3-dimethylaminopropyl)carbodiimide hydrochloride (EDC), N-hydroxysulfosuccinimide (NHS) and 2-morpholinoethane (MES) were purchased from Fluka BioChemika. All other reagents and solvents of analytical grade were supplied by POCh Poland and used as received.

\subsection{Preparation of samples}

All experiments were carried out using collagen films as a model substrate. For film preparation, the collagen dispersion at $0.4 \% \mathrm{w} / \mathrm{v}$ after deaeration was cast on the dish and then dehydrated by slow drying under a laminar air-flow to obtain an appropriate film. Some collagen films without any further treatment were taken as controls. Other films, were dehydrothermally (DHT) cross-linked by heating them at $80^{\circ} \mathrm{C}$ for $48 \mathrm{~h}$ under a vacuum of 50 mTorr. Thereafter, collagen films were cross-linked using EDC with NHS/MES. This 
procedure was also used to immobilize HA onto the collagen. Then, the films after DHT treatment were subsequently cross-linked by water-soluble EDC/NHS system in presence of HA, similarly to the method described previously for collagen and chondroitin sulfate (CS) [23] with a minor modification [24]. The addition NHS increases the rate and degree of crosslinking [25] and MES minimizes hydrolysis of EDC [26]. Finally, the matrices were rinsed with distilled water and dehydrated again by slow drying under a laminar flow hood. The content of immobilized HA in collagen films determined with the use of the pdimethylaminobenzaldehyde reaction amounted to $(6.0 \pm 1.1) \%$. More results and the procedure this examination are given in [24].

\subsection{Dielectric measurements}

Measurements of the complex permittivity $\varepsilon^{*}\left(\varepsilon^{*}=\varepsilon^{\prime}-\mathrm{j} \varepsilon^{\prime \prime}\right)$ and conductivity $\sigma\left(\sigma=2 \pi f \varepsilon_{0} \varepsilon^{\prime \prime}\right)$ were carried out using an impedance analyser HIOKI 3522-50 LCR over the frequency, $\mathrm{f}$, range of $10 \mathrm{~Hz}-100 \mathrm{kHz}$ and in temperatures, $\mathrm{T}$, from 22 to $260^{\circ} \mathrm{C}$. Prior to the dielectric measurement the largest surfaces of the unmodified and modified collagen samples were covered with silver paste electrodes. All samples were approximately $6 \times 3 \times 0.05 \mathrm{~mm}^{3}$ rectangular slabs. Two sets of samples were studied: air-dried at room temperature of relative humidity of $\sim 70 \%$ termed 'wet' and the one devoid of loosely bound water at room temperature termed 'dry'. In order to obtain the dry state of the sample, prior to the measurements this sample was kept in the measuring cell at a temperature about $120^{\circ} \mathrm{C}$ for $2 \mathrm{~h}$. In our earlier studies [46] we determined the time in which the dielectric parameters of collagen reached constant values and temperature which was sufficient to extract all of the loosely bound water present in the collagen. Following this procedure, the sample was cooled to room temperature and subjected in a similar way as the wet sample to the dielectric measurements in the cycle of heating from room temperature to $260^{\circ} \mathrm{C}$ at a rate of about $1{ }^{\circ} \mathrm{C} / \mathrm{min}$. The temperature of the unmodified and modified collagen sample was measured by a constantan-copper thermocouple. The electromotive force of the thermocouple was indicated by a digital voltmeter. The temperature controller (type 650, UNIPAN, Poland) was connected to an electric heater in the sample cell. The results were recorded by a computer. In addition, the dielectric studies of collagen we supplemented with measurements of weight loss of this material. Therefore, a few unmodified and HA-modified collagen samples obtained according to the same procedure as those for dielectric experiments were placed in the measuring cell. Then the samples were subjected to the cycles of heating as a function of temperature or as a function of time at $120^{\circ} \mathrm{C}$. During these cycles the samples were taken out, 
weighed and the weight loss in them was determined to their weight at room temperature. The weight loss of unmodified and HA-modified collagen samples that were kept for $2 \mathrm{~h}$ at $120^{\circ} \mathrm{C}$ was about 11 and $13 \%$, respectively.

Previously [24], the collagen drying process has been also studied by differential scanning calorimetry (DCS) and thermogravimetric analysis (TGA).

\section{Results}

Figs. 1a and $\mathrm{b}$ show the plots of the relative permittivity $\varepsilon^{\prime}$ and dielectric loss $\varepsilon^{\prime \prime}$ for the wet and dry unmodified collagen and DHT-, DHT-EDC/NHS- and DHT-EDC/NHS-HAmodified collagen at $50 \mathrm{kHz}$ versus temperature $\mathrm{T}$, respectively. In order to present the effect of frequency on the dielectric properties of wet samples these figures contain additional curve only for unmodified collagen at a chosen frequency of $5 \mathrm{kHz}$ since the character of the changes in $\varepsilon^{\prime}$ and $\varepsilon^{\prime \prime}$ for remainder materials is similar. All the plots in these figures reveal that at each temperature $\varepsilon^{\prime}$ and $\varepsilon^{\prime \prime}$ are higher in DHT-EDC/NHS- and DHT-EDC/NHS-HAmodified collagen than in the unmodified collagen and DHT-modified collagen. In addition, these parameters are much higher for DHT-EDC/NHS-HA-modified collagen than for the other materials. The curves of $\varepsilon^{\prime}$ and $\varepsilon^{\prime \prime}$ for all materials studied show the low T relaxation occurring much below $140^{\circ} \mathrm{C}$ and the high $\mathrm{T}$ relaxation as a weak maximum at around 210 $230^{\circ} \mathrm{C}$.

"Here Figs. 1(a-b)".

The results of weight loss, $\mathrm{m}$, for dry and wet unmodified collagen and DHT-EDC/NHS-HAmodified collagen associated with these relaxations and up to $260^{\circ} \mathrm{C}$ are given in Table I. A significant effect of cross-linking and water on the weight loss of collagen is evident up to $230^{\circ} \mathrm{C}$, while above this temperature all samples have lost about $11 \%$. Up to $230^{\circ} \mathrm{C}$, the weight loss of these samples are about $6 \%$ for dry and $17 \%$ for wet. In addition, the weight loss of the wet and dry unmodified collagen is higher and lower than that of DHT-EDC/NHSHA-modified collagen up to $200^{\circ} \mathrm{C}$ and in the range of $200-230^{\circ} \mathrm{C}$, respectively. In other studies performed using TGA and DSC $[24,32]$ methods the weight losses have been found to correspond to the decomposition of water up to about $230^{\circ} \mathrm{C}$ and collagen above this temperature. On the basis of the classification of water in collagen into strongly bound $(<$ $10 \%$ by weight) and loosely bound ( $>10 \%$ by weight) [34-36], we have assumed, that in our studies the dry and wet samples contained about 6 and $10 \%$ strongly bound water, respectively. 


\section{"Here Table I".}

Figs. $2 \mathrm{a}$ and $\mathrm{b}$ present the temperature dependencies of $\varepsilon^{\prime}$ and $\varepsilon^{\prime \prime}$ for all dry unmodified and modified collagen samples at $50 \mathrm{kHz}$ up to $260^{\circ} \mathrm{C}$, respectively.

"Here Figs. 2(a-b) ".

The results in these figures reveal that the appearance of the low $T$ maxima in $\varepsilon^{\prime \prime}$ for dry samples is accompanied by changes in $\varepsilon^{\prime}$ in all four materials. Similar curves to those presented in Figs. 2(a-b) were obtained over the frequency range used in our experiments. Fig. 3 shows the plots of the dielectric loss of unmodified collagen versus frequency at several temperatures. The dispersion in $\varepsilon^{\prime \prime}$ in this sample occurs in the range of $3-100 \mathrm{kHz}$, up to $100^{\circ} \mathrm{C}$.

\section{"Here Fig. 3 ".}

Fig. 4 presents the Arrhenius plots of the frequency of the dielectric loss maximum, $f_{\max }$, whose slopes yield the activation energy, $\Delta \mathrm{H}$, for the low $\mathrm{T}$ relaxation of all four materials, according to relation:

$$
\log f_{\max }=\log f_{o}-\frac{\Delta H}{2.3 R T}
$$

where, $f_{o}$ is the pre-exponential factor, $R$ is the gas constant, and $T$ is the temperature in Kelvin. The slope of the straight line corresponds to $-\Delta H / 2.3 R$. The $\Delta H$ takes values of $(57 \pm 3) \mathrm{kJ} / \mathrm{mol},(39 \pm 5) \mathrm{kJ} / \mathrm{mol}$, and $(66 \pm 4) \mathrm{kJ} / \mathrm{mol}$, for unmodified and DHT-EDC/NHS-HAmodified collagen, DHT-modified collagen, and DHT-EDC/NHS-modified collagen, respectively.

"Here Fig. 4".

The high T relaxation in Figs. 2 (a-b) is more clearly presented in Figs. 5 (a-b) for DHTEDC/NHS-HA-modified collagen at various frequencies. This relaxation shows no frequency dependence, but in this temperature range only the frequency affects the values of $\varepsilon^{\prime}$ and $\varepsilon^{\prime \prime}$. However, the curves in Fig. $5 \mathrm{~b}$ do not show a maximum of $\varepsilon^{\prime \prime}$ because this relaxation and the increasing values of $\varepsilon^{\prime \prime}$ above these temperatures overlap.

"Here Figs. 5(a-b)".

Fig. 6 compares the frequency dependencies of ac conductivity $\sigma$ at temperature of $90^{\circ} \mathrm{C}$ for dry samples.

"Here Fig. 6". 
The conductivity curves for all samples at this temperature and up to $\sim 200^{\circ} \mathrm{C}$ (not presented) show a linear behaviour with the slope of about $0.8-1.0$.

\section{Discussion}

The results in all figures illustrate the effect of different methods of cross-linking of collagen on its dielectric properties. A significant increase in the values of $\varepsilon^{\prime}$ and $\varepsilon^{\prime \prime}$ in the whole temperature range is apparent first of all for the collagen modified by the DHT and EDC/NHS as well as for that modified by DHT and EDC/NHS with HA. Probably, the increase in $\varepsilon^{\prime}$ and $\varepsilon^{\prime \prime}$ in the collagen modified by these methods is a result of the cross-linking reactions due to a greater number of charge carriers and sites available for them to accumulate and to pass current. In this study, similarly as in our previous work on collagen [27] and different biological materials reported by other authors using dielectric techniques [37, 4749], we consider protons as a charge carriers, since their presence in these materials has been confirmed by a linear frequency dependencies of $\sigma$ up to $\sim 200^{\circ} \mathrm{C}$ (Fig. 6), which are typical of the proton polarization and conduction processes. The sites are created by newly formed intraand intermolecular cross-links such as hydrogen, hydrogen-bound water, hydrophobic and van der Waal's essential for stability of the superhelix structure. The differences in the values of $\varepsilon^{\prime}$ and $\varepsilon^{\prime \prime}$ in Figs.1(a-b) between all modified samples at each temperature indicate that the proton transport and the ability of the proton accumulation at the phase interface is the lowest for DHT-modified collagen and the highest for DHT-EDC/NHS-HA-modified collagen. This behaviour observed for both parameters is a consequence of different density of cross-links in these materials. The interchain cross-links formed during the DHT treatment are a result of condensation reactions either by estrification or by amide formation. It is important that this process introduces covalent cross-links between the polypeptide chains of the collagen macromolecules without denaturing the collagen into gelatine. In fact, this denaturation manifested as a high $\mathrm{T}$ relaxation on the temperature dependencies of $\varepsilon^{\prime}$ and $\varepsilon^{\prime \prime}$ in Figs. 1 and 2 (a-b) occurs in the same temperature range for unmodified and DHT-modified collagen, and also for the remaining samples. In addition, the results presented in these figures reveal that the cross-linking of collagen with DHT effects only $\varepsilon^{\prime \prime}$ but not $\varepsilon^{\prime}$ as the values of the latter are similar to those for the unmodified collagen. This indicates, that the electric current flowing through the DHT sample is higher than that in the unmodified sample. In addition, little difference observed in $\varepsilon^{\prime}$ over the entire temperature range between DHT-modified and unmodified collagen suggests that the newly formed cross-links do not contain sites available 
to accumulation of protons. The primary advantage of the DHT method of cross-linking is that it does not introduce chemicals. The most important problem that should be taken into consideration when collagen products are applied in medicine is the toxicity of the agent used for cross-linking. On the other hand, the main disadvantage of the DHT treatment is that it generally provides a low density of cross-links. Therefore, to prepare collagen-HA scaffolds, collagen is first dehydrated by a combination of thermal and vacuum drying (DHT) and then treated with the chemical reagent carbodiimide (EDC/NHS) for final cross-linking. The water-soluble carbodiimide reagent offers another possibility for generation of cross-links between the corresponding reaction sites, without itself being incorporated. Fig. 7 shows the sequence of events in a typical reaction.

"Here Fig. 7".

In the presence of NHS, the O-acylisourea group is converted to the NHS-activated carboxylic acid group which reacts with a free amine group of lysine or hydroxylysine of collagen. A consequence of the chemical cross-linking of collagen with the use carbodiimide are much higher values of $\varepsilon^{\prime}$ and $\varepsilon^{\prime \prime}$ in Figs. 1(a-b) for DHT-EDC/NHS-modified collagen than for DHT-modified collagen. This suggests that the former must have a greater ability to proton transport through the newly formed intra- and intermolecular hydrogen bonds and also to store polarizable charges at the phase interface. The data for DHT-EDC/NHS-HA-modified collagen in these figures also show that the polarization and conduction mechanisms become more important when collagen is cross-linked with DHT and EDC/NHS in the presence of HA. The typical reactions occurring in the collagen-HA system with a mixture of EDC and NHS/MES were presented in our earlier publication [24]. This procedure to prepare collagen modified by HA may be explained by a possible simultaneous occurrence of two reactions: collagen-collagen cross-linking and covalent grafting of HA to the collagen backbone, resulting in the formation of semi-interpenetrating polymer network.

The degree of cross-linking of collagen with DHT, EDC/NHS and HA affects not only the values of $\varepsilon^{\prime}$ and $\varepsilon^{\prime \prime}$ but also the temperature range of the low T relaxation as seen in Fig. 4. A distinct shift of the low-frequency dispersion of DHT-modified collagen towards higher temperatures relative to that of unmodified collagen is a result of the dehydrothermal method of cross-linking, which removes water from collagen. This treatment has no significant effect on the amplitude of the peaks in the low $\mathrm{T}$ relaxation relative to those recorded for unmodified samples. However, the shift of the low $\mathrm{T}$ relaxation of DHT-EDC/NHS- and DHT-EDC/NHS-HA-modified collagen towards lower temperatures relative to those of 
unmodified collagen can indicate that the cross-links tend to act as their own plasticizer in this temperature range.

Fig.1 also presents the effect of water on the dielectric properties of all the materials studied. The curves of $\varepsilon^{\prime}$ and $\varepsilon^{\prime \prime}$ in the low T relaxation for wet and dry samples indicate that loosely bound water in wet samples masks the effect of frequency on these parameters. This relaxation is associated with the breaking of inter- and intra-molecular hydrogen bonds including these formed between water molecules and the chains or between the carbonyl group on one chain and the amide hydrogen on another chain within groups of three amino acids [28]. For wet samples, a consequence of breaking of the intermolecular bonds is the release of loosely bound water manifested by the $\varepsilon^{\prime}$ and $\varepsilon^{\prime \prime}$ maxima occurring around $60-70^{\circ} \mathrm{C}$ for DHT- and DHT-EDC/NHS-modified collagen and below the temperatures used in the measurements for DHT-EDC/NHS-HA-modified collagen. But the temperatures of these peaks are nearly independent of frequency and only the dry samples that do not contain loosely bound water reveal the effect of frequency on the low T relaxation. As shown in Table I, up to $200^{\circ} \mathrm{C}$ at which temperature the minimum in $\varepsilon^{\prime \prime}$ appears, the weight losses in wet unmodified collagen correspond to the loosely bound water and a great deal of strongly bound water, while wet HA-modified collagen releases only the loosely bound water. In the same temperature range, dry unmodified sample lost almost the total weight of strongly bound water present in collagen, by contrast to the dry HA-modified sample in which no weight loss was observed. In fact, thanks to the cross-linking processes the presence of water in HAmodified collagen is responsible for the higher thermal stability of this material relative to that of the unmodified collagen. An increase in the structural order of this modified collagen increases its resistance to biodegradation because of the appearance of the new links limiting the accessibility to cleavage sites and preventing penetration of the enzymes into the material [31]. In addition, the HA-cross-linked-collagen is attractive for its biocompatibility and therefore has been utilized as a tissue engineering scaffold. As a results, the cell, enzyme or ion may be entrapped in a collagen matrix.

The loosely bound water in wet samples also affects the high $\mathrm{T}$ relaxation masking the polarization and conduction mechanisms assigned with the conformational changes in the superhelix. This relaxation in Fig.1 (a-b) is better shown in Figs. 8 (a-b) for one chosen sample of unmodified collagen. As seen in Fig. 8a, the high T relaxation for wet samples is depressed $\left(\sim 215^{\circ} \mathrm{C}\right)$ when compared to that of the dry samples $\left(\sim 230^{\circ} \mathrm{C}\right)$. It is a result of the plasticizing effect of water [29] that decreases the packing density of the main chains of 
collagen and facilitates the motion of the chains. It should be emphasised that the temperature range of the high T relaxation is the same for unmodified and modified collagen. Previously, the occurrence of denaturation phase transition of collagen in the solid state has been confirmed by other thermal methods $[24,32,33,44]$. This denaturation behaviour of collagen involves liberation of the residual strongly bound water and a rearrangement of the triple helix into a random configuration. Gelatin can be considered as a denatured form of collagen because of chain-chain association [31]. In addition, as follows from literature data [18], the chemical changes in the triple helical structure of the collagen molecule do not occur even though the water concentration is low of about $3 \%$. The results of this paper and our earlier dielectric studies of collagen $[27,45,50]$ confirm the appearance of the denaturation process in collagen above $200^{\circ} \mathrm{C}$ reported by other authors. In fact, the weight loss of wet and dry samples in the range $200-230^{\circ} \mathrm{C}$ given in Table I corresponds to the release of strongly bound water. However, in the case of HA-modified collagen this total unreleased water in the lower temperatures is just now extracted, whereas the unmodified sample lost the rest of the water content in collagen. These results indicate, that the collagen modified by HA, the triple helix is thermally stable even up to $230^{\circ} \mathrm{C}$ thanks to the cross-links with the strongly bound water, which is released only near this temperature.

Fig. 8 also presents additional plots (1) and (2) for the second heat cycle of wet unmodified samples which were immediately cooled to room temperature after the first cycle of heating to 200 and $260^{\circ} \mathrm{C}$, respectively. On the basis of the Table I data we have assumed that curves (1) and (2) are attributed to the samples containing about 2.5 and $0 \%$ water, respectively. In fact, the weak peak of $\varepsilon^{\prime}$ around $230^{\circ} \mathrm{C}$ in curve (1) corresponds to the release of water, whereas the continuous increase in $\varepsilon^{\prime}$ for curve (2) indicates the absence of water in this sample. In addition, the plot (2) shows the low T relaxation similarly as in the plot (1). This suggests that in the sample with $0 \%$ water content the chemical deterioration of collagen macromolecules which has already begun above the high $\mathrm{T}$ relaxation on the first heating, does not involve hydrogen bonds. The occurrence of the peaks in $\varepsilon$ ' for vacuum dried collagen in the same temperature range has been confirmed by other authors [38].

\section{Conclusions}

The results of this study performed by the dielectric spectroscopy over a wide range of temperatures provide new information on molecular interactions in cross-linked collagen. Cross-linking and grafting of the collagen film by HA is an effective way not only to slow 
down the biodegradation rate but also to optimize the dielectric properties of these systems. In fact, in the whole temperature range the dielectric parameters are much higher for HAmodified collagen than for unmodified collagen because of the greater number of sites among which protons can jump and mobility of these carriers in the former. 


\section{References}

[1] L.J. Bonassar, C.A. Vacanti, Tissue Engineering: The First Decade and Beyond, J Cell. Biochem. 30/31 (1998) 297-303.

[2] J.E. Babensee, J.M. Anderson, L.V. McIntire, A.G. Mikos, Host response to tissue engineered devices, Adv. Drug. Deliver. Rev. 33 (1998)111-139.

[3] R. Cancedda, B. Dozin, P. Giannoni, R. Quarto, Tissue engineering and cell therapy of cartilage and bone, Matrix Biology 22 (2003) 1-91.

[4] J.B. Leach, C.E. Schmidt, Characterization of protein release from photocrosslinkable hyaluronic acid-polyethylene glycol hydrogel tissue engineering scaffolds, Biomaterials 26 (2005)125-135.

[5] M.H. Fittkau, P. Zilla, D. Bezuidenhout, et al., The selective modulation of endothelial cell mobility on RGD peptide containing surfaces by YIGSR peptides, Biomaterials 26 (2005) 167-174.

[6] Q. Lu, K. Ganensan, D.T. Simionescu, et al., Novel porous aortic elastin and collagen scaffolds for tissue engineering, Biomaterials 25 (2004) 5227-5237.

[7] F.J. O’Brien, B.A. Harley, I.V. Yannas, et al., The effect of pore size on cell adhesion in collagen-GAG scaffolds, Biomaterials 26 (2005) 433-441.

[8] R. Zeeman, P.J. Dijkstra, P.B. van Wachem, M.J.A. van Luyn, M. Hendriks, P.T. Cahalan, J. Feijen, Successive epoxy and carbodiimide cross-linking of dermal sheep collagen, Biomaterials 20 (1999) 921-931.

[9] T. Segura, B.C. Anderson, P.H. Chung, R.E. Webber, K.R. Shull, L.D. Shea, Crosslinked hyaluronic acid hydrogels: a strategy to functionalize and pattern, Biomaterials 26 (2005) 359-371.

[10] K. Matsumoto, K. Ohnishi, T. Kiyotan, T. Sekine, et al., Pheripherial nerve regeneration across an $80-\mathrm{mm}$ gap bridged by a PGA-collagen tube filled with laminin-coated collagen fibers: a histological and electrophysiological evaluation of regenerated nerves, Brain. Res. 868 (2000) 315-328.

[11] A. Gamini, S. Paoletti, R. Toffanin, F. Micali, L. Michielin, C. Bevilacqua, Structural investigations of cross-linked hyaluronan, Biomaterials 23 (2002) 1161-1167.

[12] S.N. Park, J.K. Kim, H. Suh, Evaluation of antibiotic-loaded collagen-hyaluronic acid matrix as a skin substitute, Biomaterials 25 (2004) 3689-3698.

[13] L-S. Liu, A.Y. Thompson, M.A. Heidaran, J.W. Poser, R.C. Spiro, An osteoconductive collagen/hyaluronate matrix for bone regeneration, Biomaterials 20 (1999) 1097-1108. 
[14] M. Radice, P. Brun, R. Cortive, R. Scapinelli, C. Battaliard, G. Abatangelo, Hyaluronan-based biopolymers as delivery vehicles for bone-marrow-derived mesenchymal progenitors, J. Biomat. Mater. Res. 50 (2000)101-109.

[15] S.N. Park, H.J. Lee, K.H. Lee, H. Suh, Biological characterization of EDC-crosslinked collagen-hyaluronic acid matrix in dermal tissue restoration, Biomaterials 24 (2003) 1631-1641.

[16] H.K. Kleinman, R.G.R. Klebe, G.R. Martin, Role of collagenous matrices in the adhesion and growth of cells, J. Cell. Biol. 88 (1981) 473-481.

[17] T. Fujisato, T. Sajiki, Q. Liu, Y. Ikada, Effect of basic fibroblast growth factor on cartilage regeneration in chondrocyte-seeded collagen sponge scaffold, Biomaterials 22 (2002) 3145-3154.

[18] W. Friess, G. Lee, Basic thermoanalytical studies of insoluble collagen matrices, Biomaterials 17(1996) 2289-2294.

[19] C.C. Silva, A.G. Thomazini, A.G. Pinheiro, N. Aranha, S.D. Figueiro, J.C. Goes, A.S.B. Sombra, Collagen-hydroxyapatite films: piezoelectric properties, Materials Science and Engineering B86 (2001) 210-218.

[20] S.D. Figueiro, J.C. Goes, R.A. Moreira, A.S.B. Sombra, On the physico-chemical and dielectric properties of glutaraldehyde crosslinked galactomannan-collagen films, Carbohydrate Polymers 56 (2004) 313-320.

[21] K. Pietrucha, E. Marzec, Dielectric properties of the collagen-glycosaminoglycans scaffolds in the temperature range of thermal decomposition, Biophysical Chemistry 118 (2005) 51-56.

[22] K. Pietrucha, Effect of irradiation on collagen solutions in relation to biomedical applications, Polymers in Medicine 19 (1989) 3-18.

[23] J.S. Pieper, A. Oosterhol, P.J. Dijakstra, J.H. Veerkamp, T.H. van Kuppevelt, Crosslinked hyaluronic acid hydrogels: a strategy to functionalize and pattern, Biomaterials 20 (1999) 847-858.

[24] K. Pietrucha, Changes in denaturation and rheological properties of collagen hyaluronic acid scaffolds as a result of temperature dependencies, Int. J. Biol. Macromol. 36 (2005) 299-304.

[25] L.H.H. Olde Damink, P.J. Dijkstra, M.J.A. van Luyn, P.B. van Wachem, J. Feijen, Cross-linking of dermal sheep collagen using a water-soluble carbodiimide, Biomaterials 17 (1996) 765-773. 
[26] M.A. Gilles, A.Q. Hudson, C.L. Borders, Stability of water-soluble carbodiimides in aqueous solutions, Anal. Biochem. 184 (1990) 244-248.

[27] E. Marzec, W. Warchoł, Dielectric properties of a protein-water system in selected animal tissues, Bioelectrochemistry 65 (2005) 89-94.

[28] F.H. Silver, D.L. Christiansen, Biomaterials Science and Biocompatibility, SpringerVerlag: New York, 1999.

[29] Yu.I. Matveev, V.Ya. Grinberg, V.B. Tolstoguzov, The plasticizing effect of water on proteins, polysaccharides and their mixtures. Glassy state of biopolymers, food and seeds, Food Hydrocolloids 14 (2000) 425-437.

[30] T. J. C. Faes, H. A. van der Meij, J. C. de Munck, R. M. Heethaar, The electric resistivity of human tissues $(100 \mathrm{~Hz}-10 \mathrm{MHz})$ : a meta-analysis of review studies, Physiol. Meas. 20 (1999) R1-R10.

[31] F. L. Nicolas, C. H. Gagnieu, Denatured thiolated collagen, Biomaterials 18 (1997) $815-821$.

[32] J. J. Lim, M.H. Shamos, Evaluation of kinetic parameters of thermal decomposition of native collagen by thermogravimetric analysis, Biopolymers 13 (1974) 1791-1807.

[33] I. V. Yannas, Collagen and gelatin in the solid state, J. Macomol. Sci.-Revs. Macromol. Chem. C7(1) (1972) 49-104.

[34] M. H. Pineri, M. Escoubes, G. Roche, Water-collagen interactions: calorimetric and mechanical experiments, Biopolymers 17 (1978) 2799-2815.

[35] J. R. Grigera, H. J. C. Berendsen, The molecular details of collagen hydration, Biopolymers 18, (1979) 47-57.

[36] M. Luscher-Mattli, M. Ruegg, Thermodynamic functions of biopolymer hydration. I. Their determination by vapor pressure studies, discussed in an analysis of the primary hydration process, Biopolymers 21 (1982) 403-418.

[37] M. Gulino, P. Bellia, F. Falciglia, F. Musumeci, A. Pappalardo, A. Scordino, A. Triglia, Role of water in dielectric properties and delayed luminescence of bovine Achilles' tendon, FEBS Letters 579 (20005) 6101-6104.

[38] T. Z. Rizvi, M. A. Khan, Dielectric relaxation in slightly hydrated bovine tendon collagen, J. Phys. D: Appl. Phys. 40 (2007) 25-30.

[39] I. G. Mogilner, G. Ruderman, J. R. Grigera, Collagen stability, hydration and native state, Journal of Molecular Graphics and Modelling 21 (2002) 209-213. 
[40] E. Y. Lau, V. V. Krishnan, Temperature dependence of protein-hydration hydrodynamics by molecular dynamics simulations, Biophysical Chemistry 130 (2007) 55-64.

[41] J. Kopp, M. Bonnet, J. P. Renou, Effect of collagen crosslinking on collagen-water interactions (A DSC investigation), Matrix 9 (1989) 443-450.

[42] A. Bigi, A. M. Fichera, N. Roveri, M. H. J. Koch, Structural modifications of air-dried tendon collagen on heating, Int. J. Biol. Macromol. 9 (1987) 176-180.

[43] N. Barbani, M. G. Cascone, P. Giusti, L. Lazzeri, G. Polacco, G. Pizzirani, Bioartificial materials based on collagen: 2. Mixtures of soluble collagen and poly(vinylalcohol) cross-linked with gaseous glutaraldehyde, J. Biomater. Sci. Polymer Edn. 7 (1995) 471-484.

[44] V. Samouillan, A, Lamure, C. Lacabanne, Dielectric relaxations of collagen and elastin in the dehydrated state, Chem. Phys. 255 (2000) 259-271.

[45] F. Jaroszyk, E. Marzec, Dielectric properties of BAT collagen in the temperature range of thermal denaturation, Ber.Bunsenges.Phys.Chem. 97 (1993) 868-872.

[46] E. Marzec, L. Kubisz, Electric properties of non-irradiated and gamma-irradiated bone, J. Non-Cryst. Solids 305 (2002) 333-338.

[47] R. Pethig, Protein-water interactions determined by dielectric methods, Annu. Rev. Phys. Chem. 43 (1992) 177-205.

[48] A. A. Konsta, J. Laudat, P. Pissis, Dielectric investigation of the protonic conductivity in plant seeds, Solid State Ionics 97 (1997) 97-104.

[49] P. M. Suherman, P. Taylor, G. Smith, Low frequency dielectric study on hydrated ovalbumin, J. Non-Cryst. Solids 305 (2002) 317-321.

[50] F. Jaroszyk, E. Marzec, The effect of ionizing radiation on dielectric properties of bovine achilles tendon collagen in the temperature range of thermal denaturation, $\mathrm{J}$. Mater. Sci. 29 (1994) 5353-5356. 


\section{Figure captions}

Fig. 1. Temperature dependencies of the relative permittivity (a) and dielectric loss (b) for unmodified collagen ( $\boldsymbol{\bullet}$ wet, $\square$ dry), DHT-modified collagen ( $\boldsymbol{\Delta}$ wet, $\triangle$ dry), DHTEDC/NHS- modified collagen $(\bullet$ wet, o dry), DHT-EDC/NHS-HA-modified collagen ( $\bullet$ wet, $\diamond$ dry) at $50 \mathrm{kHz}$ and for unmodified collagen (* wet) at $5 \mathrm{kHz}$.

Fig. 2. Temperature dependencies of the relative permittivity (a) and dielectric loss (b) for dry unmodified collagen $(\square)$, DHT-modified collagen $(\triangle)$, DHT-EDC/NHS- modified collagen $(\circ)$ and DHT-EDC/NHS-HA-modified collagen $(\diamond)$ at $50 \mathrm{kHz}$.

Fig. 3. Frequency dependencies of the dielectric loss for dry unmodified collagen at several temperatures of $\square 30^{\circ} \mathrm{C}, 40^{\circ} \mathrm{C}, \triangle 50^{\circ} \mathrm{C}, \times 70^{\circ} \mathrm{C}, \Delta 90^{\circ} \mathrm{C}, \circ 110^{\circ} \mathrm{C}$.

Fig. 4. Plots of $\log \left(f_{\max }\right)$ vs. $(T)^{-1}$ for unmodified collagen $(\circ)$, DHT-modified collagen $(\square)$, DHT-EDC/NHS-modified collagen $(+)$ and DHT-EDC/NHS-HA-modified collagen $(\triangle)$.

Fig. 5. Temperature dependencies of the relative permittivity (a) and dielectric loss (b) of dry DHT-EDC/NHS-HA-modified collagen for the high $\mathrm{T}$ relaxation at several frequencies of $\bullet 1 \mathrm{kHz}, \Delta 10 \mathrm{kHz}, \circ 30 \mathrm{kHz},+50 \mathrm{kHz}, \boldsymbol{\square} 80 \mathrm{kHz}$

Fig. 6. Frequency dependencies of the conductivity for dry unmodified collagen $(\diamond)$, DHTmodified collagen $(\triangle)$, DHT-EDC/NHS- modified collagen $(\circ)$ and DHT-EDC/NHSHA-modified collagen ( $\square$ ) at a chosen temperature of $90^{\circ} \mathrm{C}$.

Fig. 7. Scheme of cross-linking reaction of collagen with carbodiimide.

The carbodiimide (1) is first protonated and reacts with the carboxyl function on collagen (2) to form the o-isoacylurea (3). This is followed by nucleophilic attack of the amine functions on the adjacent collagen $(4,5)$, generating the cross-link of collagen (6) and simultaneously releasing the urea derivative of the carbodiimide reagent (7). Proper post-treatment removal of the activating reagents gives a treatment with no residual chemicals.

Fig.8. Temperature dependencies of the relative permittivity (a) and dielectric loss (b) for wet (घ) and dry $(\square)$ states, and for second cycle: curve 1(०), curve $2(*)$ of unmodified collagen.

Table I. Weight loss $m$ for dry and wet unmodified collagen and DHT-EDC/NHS-HAmodified collagen at chosen temperatures. 


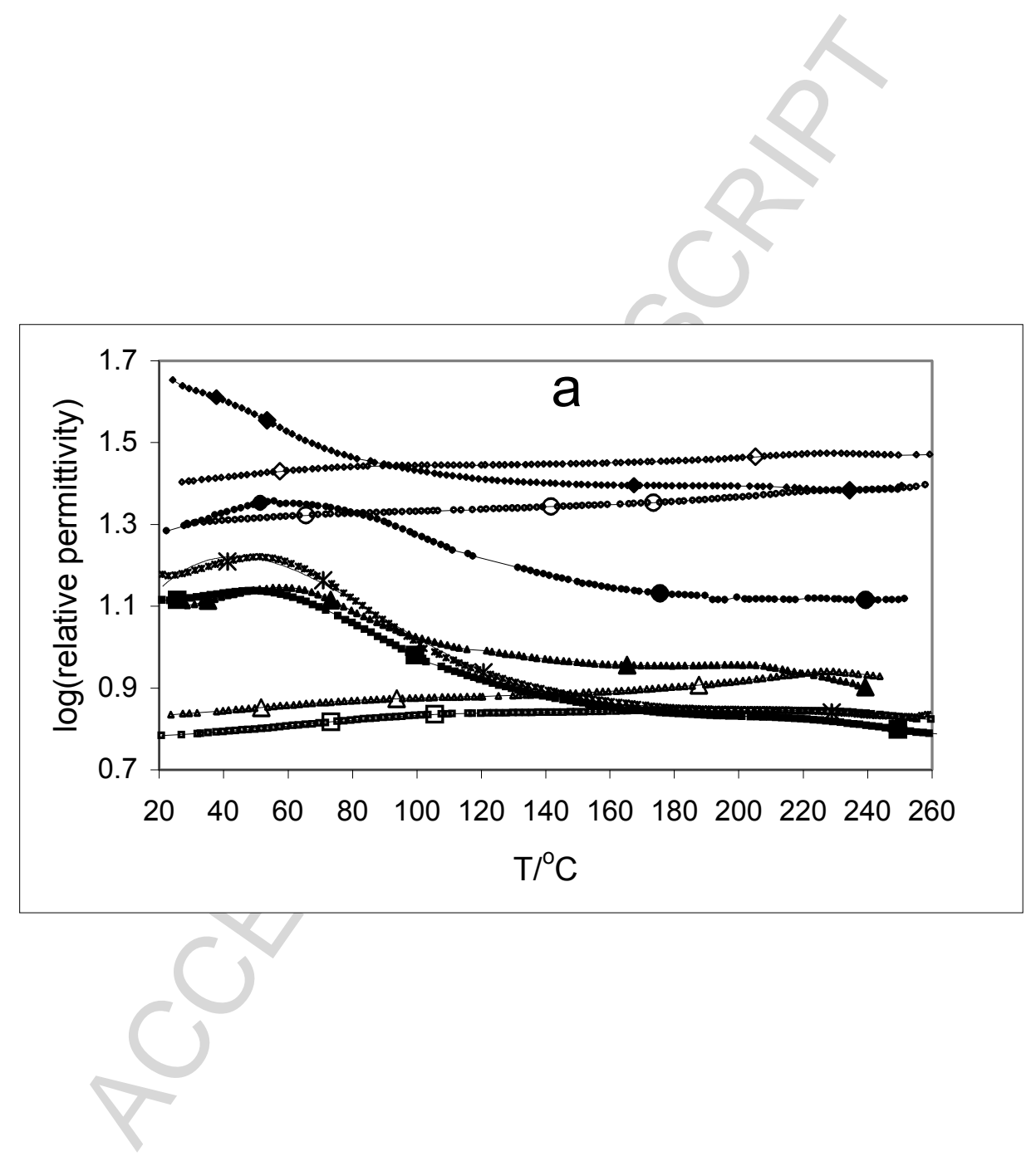

Figure 1a 


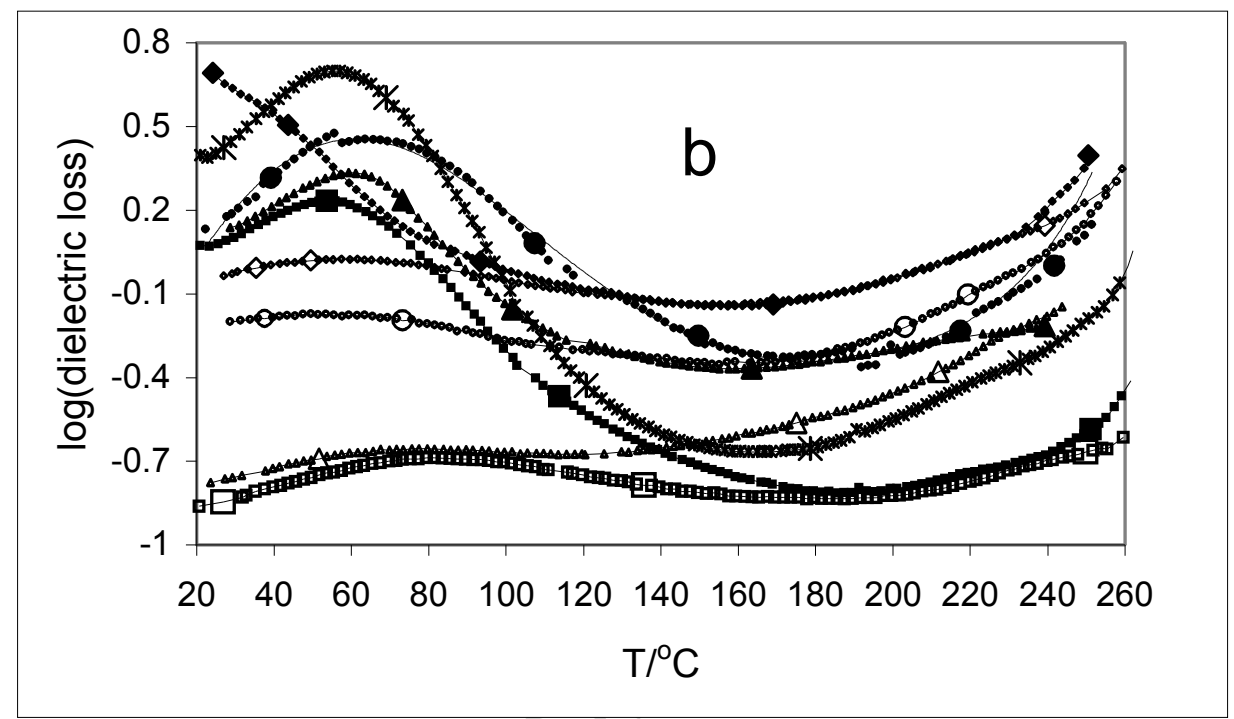

Figure 1b 


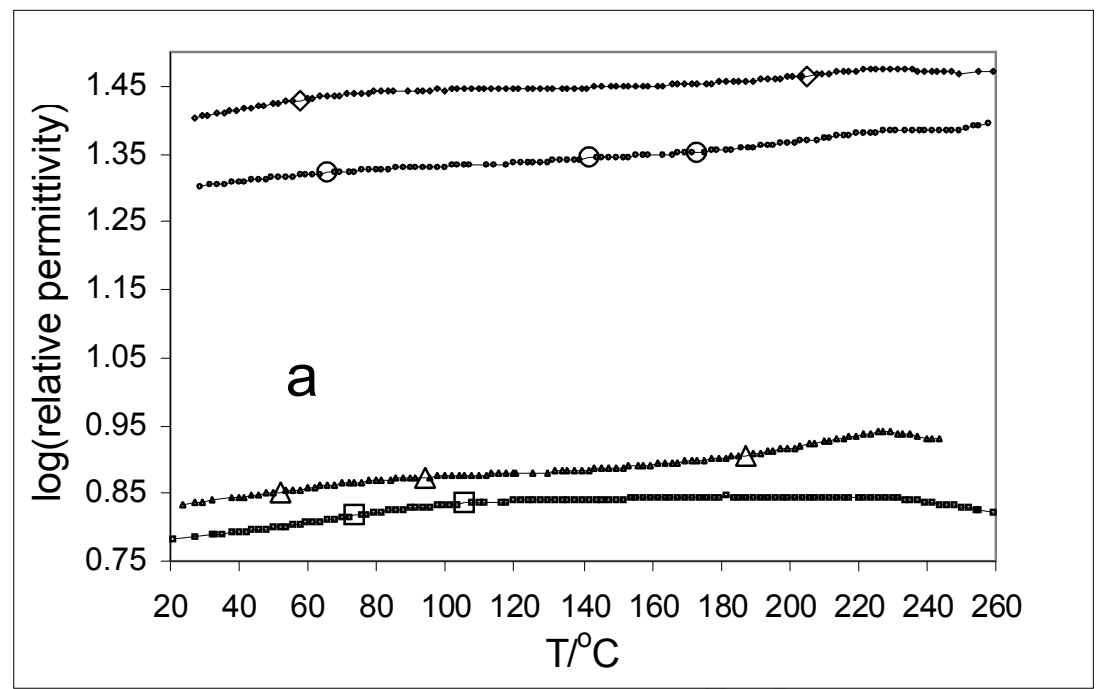

Figure $2 \mathrm{a}$ 


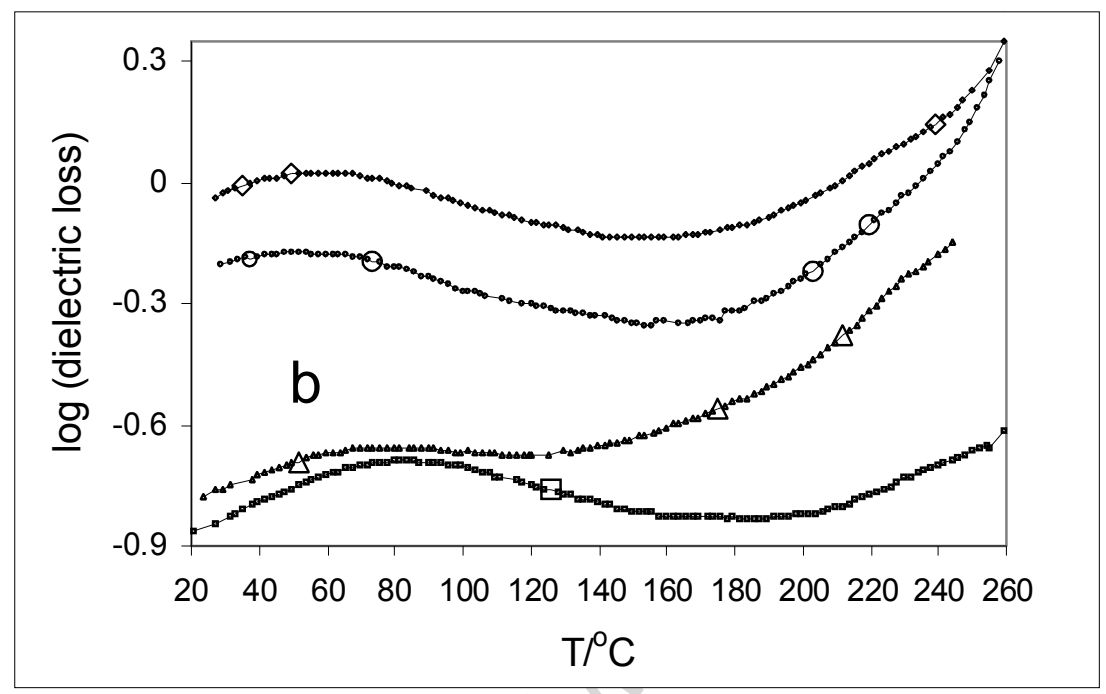

Figure $2 b$ 


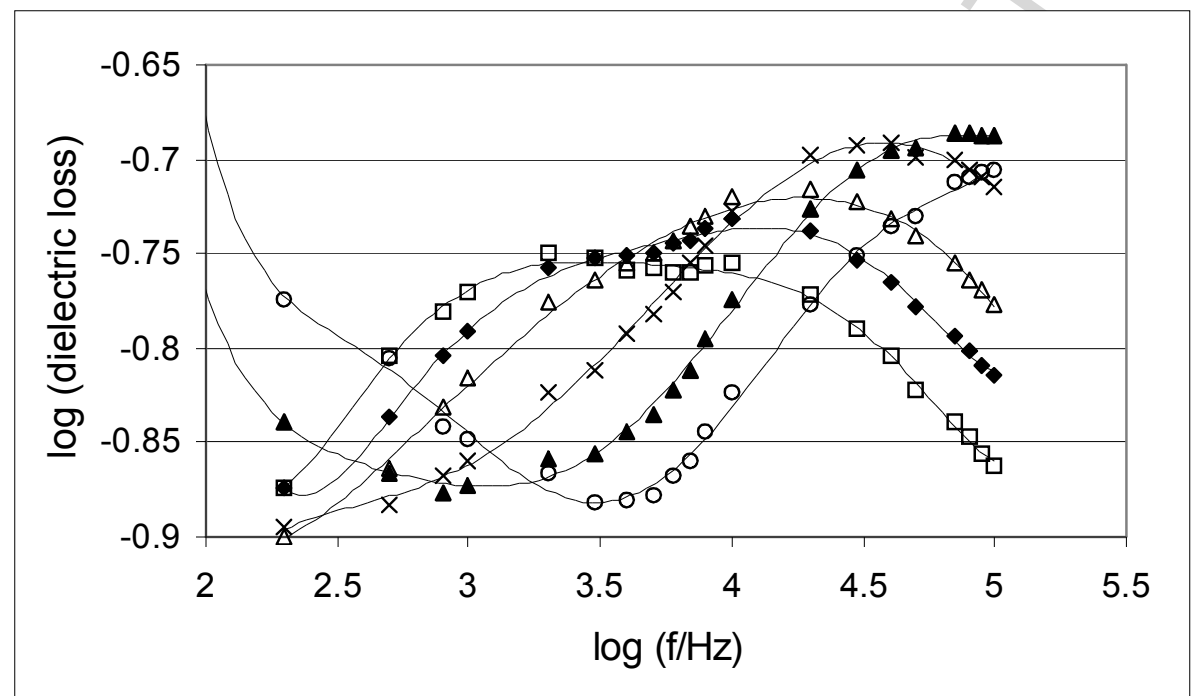

Figure 3 


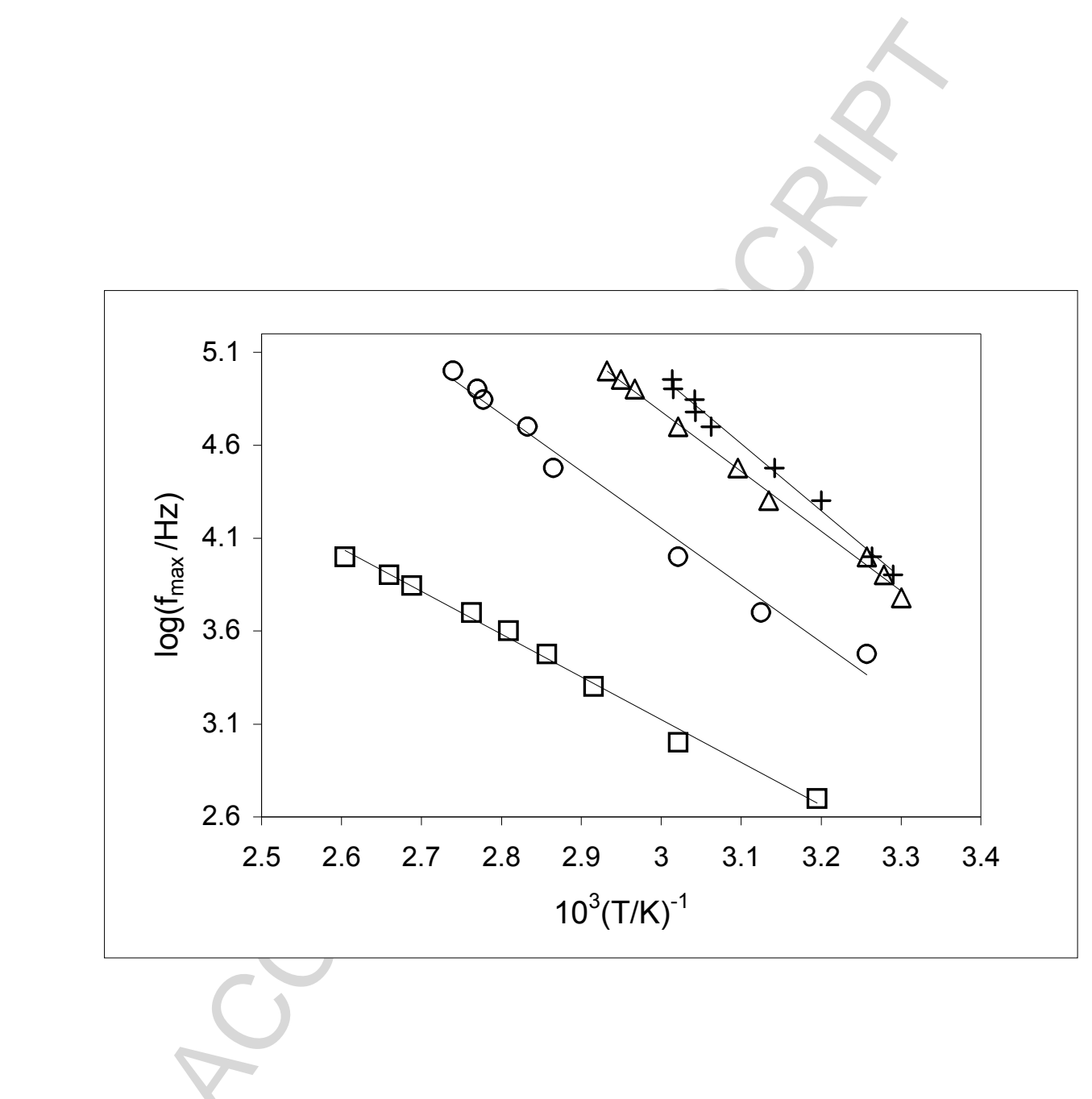

Figure 4 


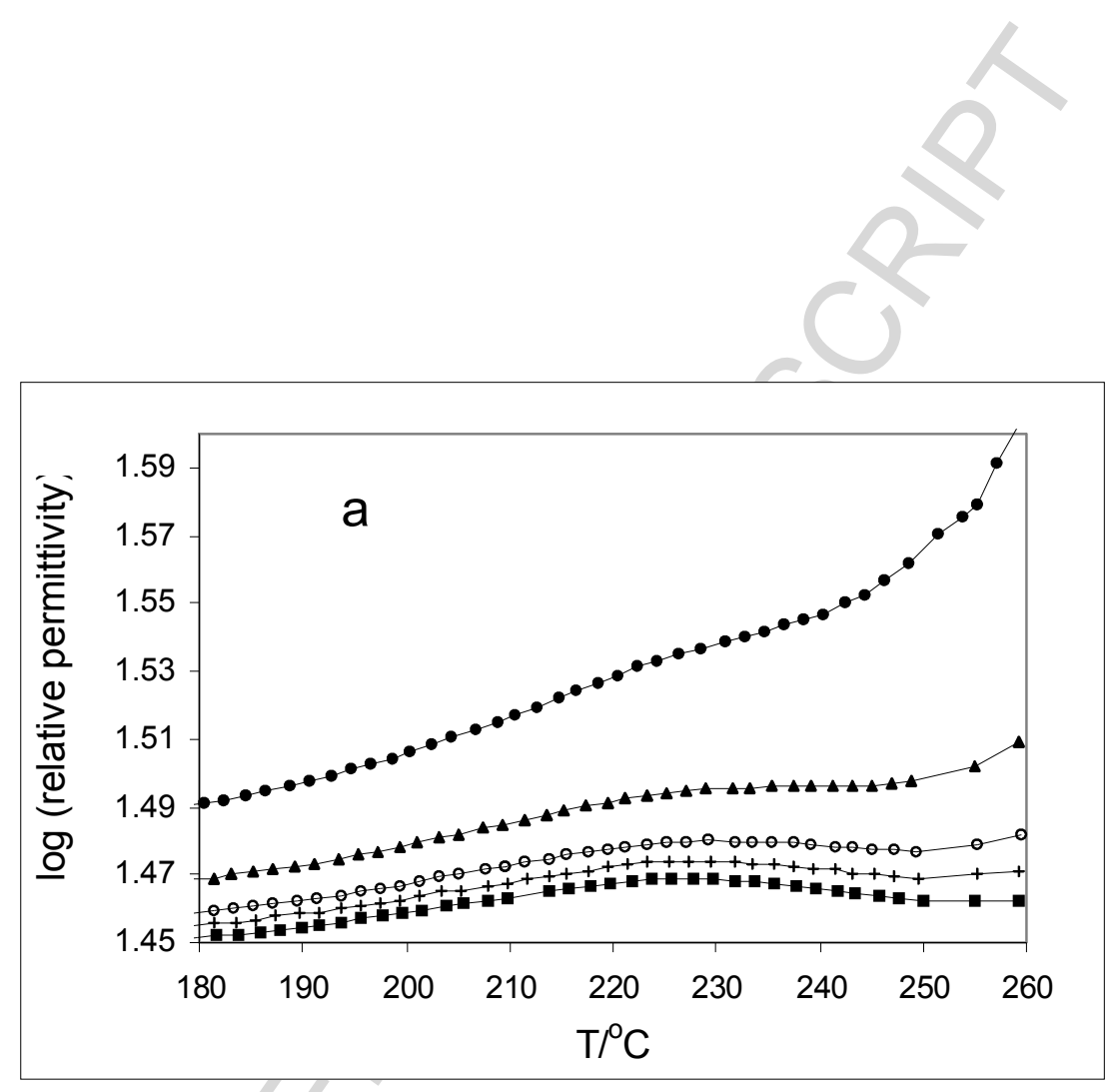

Figure $5 \mathrm{a}$ 


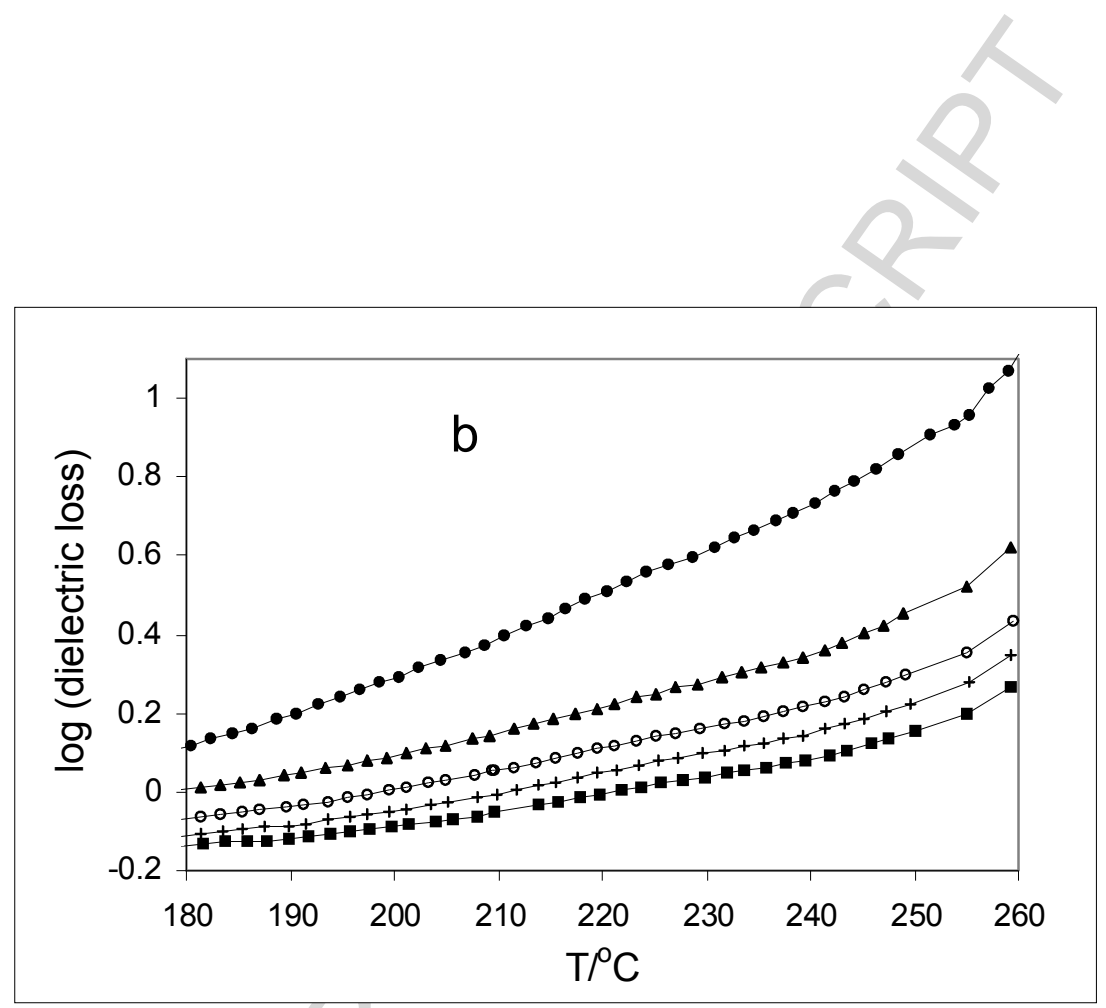

Figure $5 \mathrm{~b}$ 


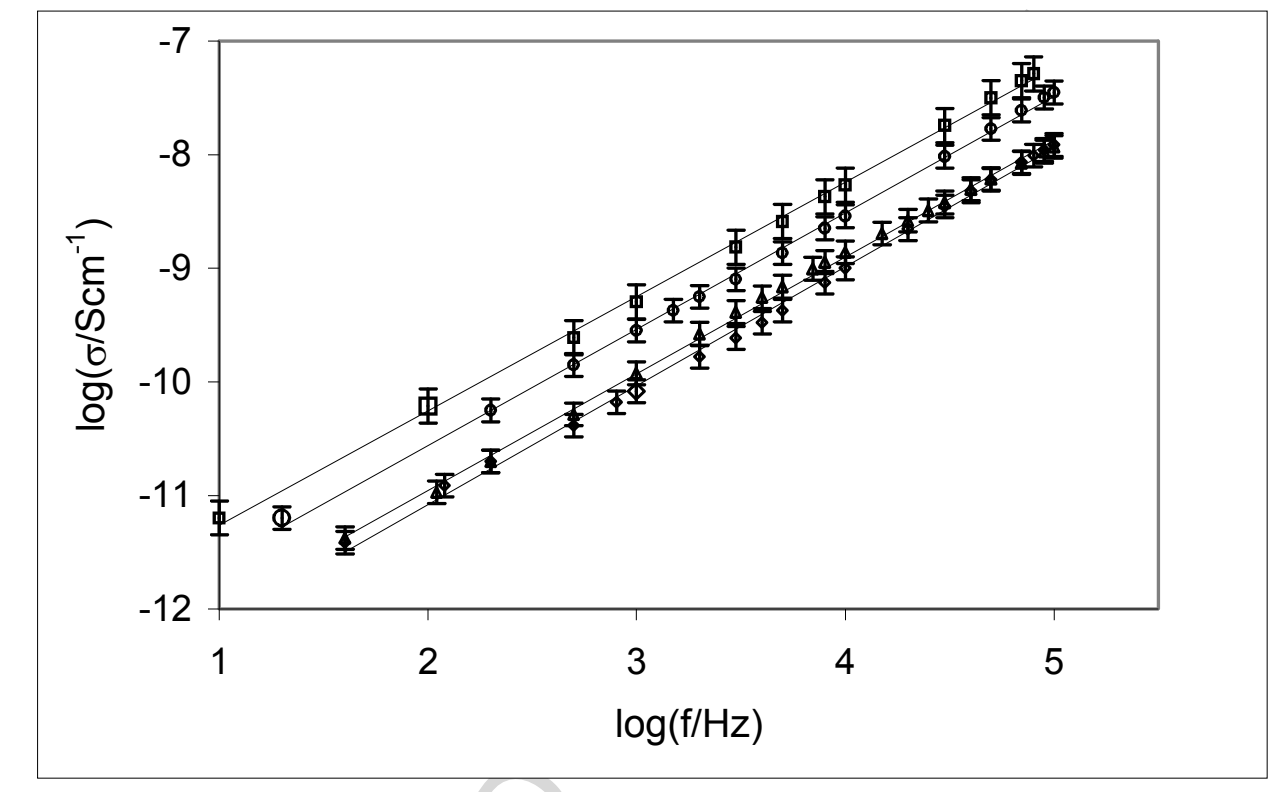

Figure 6 


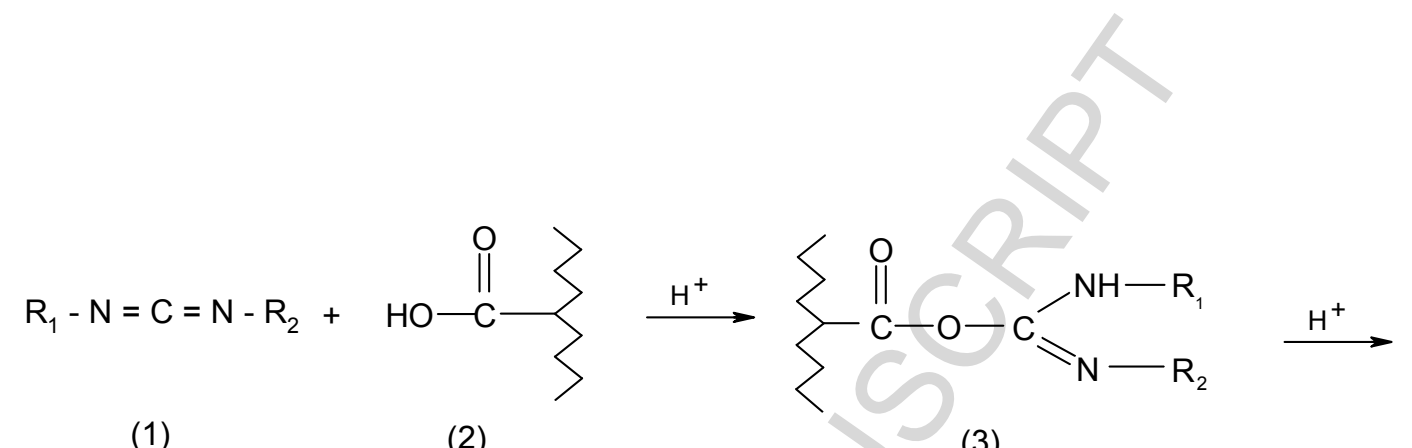

(1)

(2)

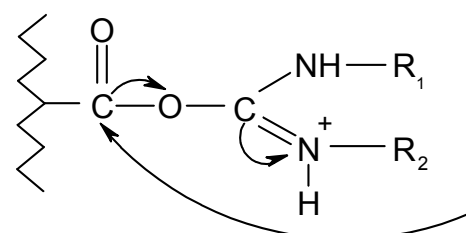

(4)<smiles>CCCCC(CCC)(CCC)NCC</smiles>

(5)<smiles>[R][R]NC(=O)N[R]</smiles>

(6)

(7)

Figure 7 


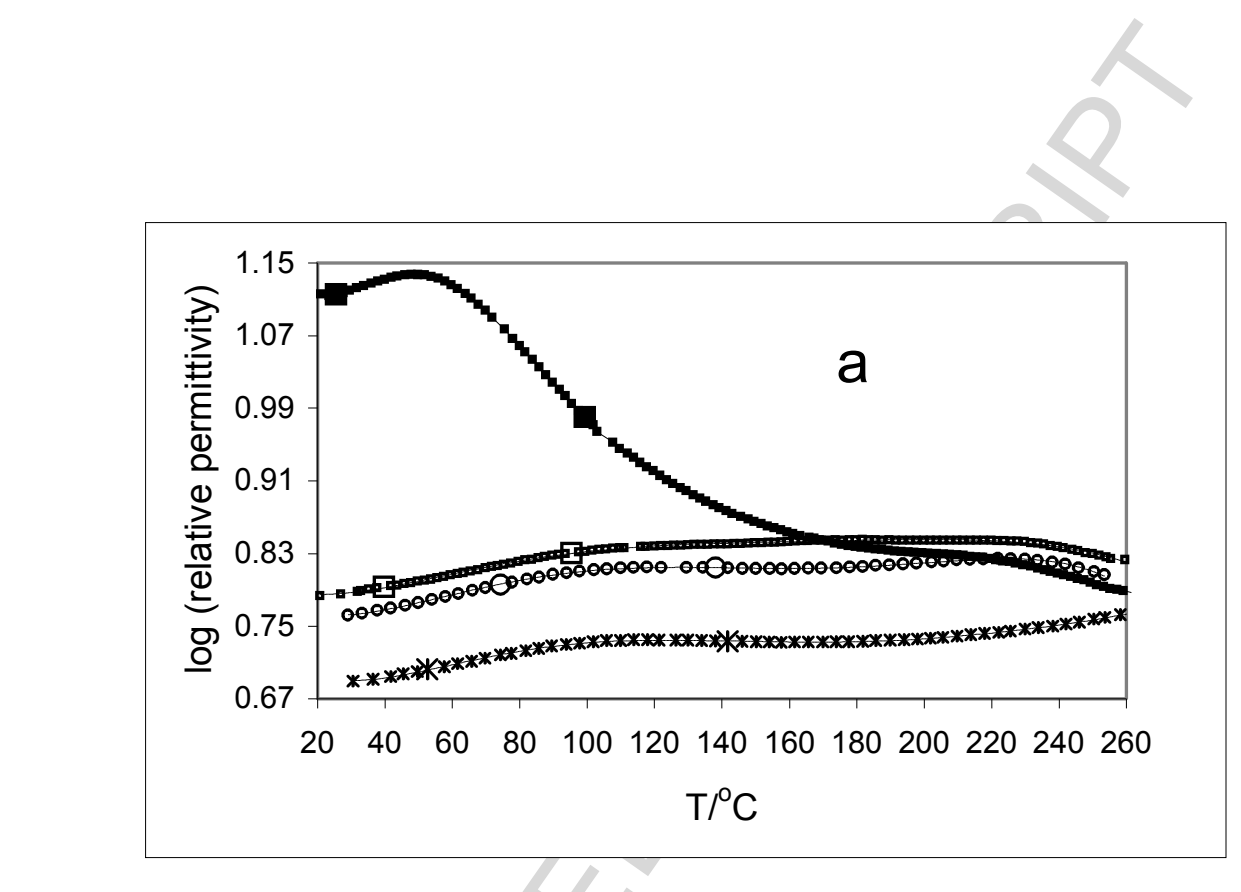

Figure 8 a 


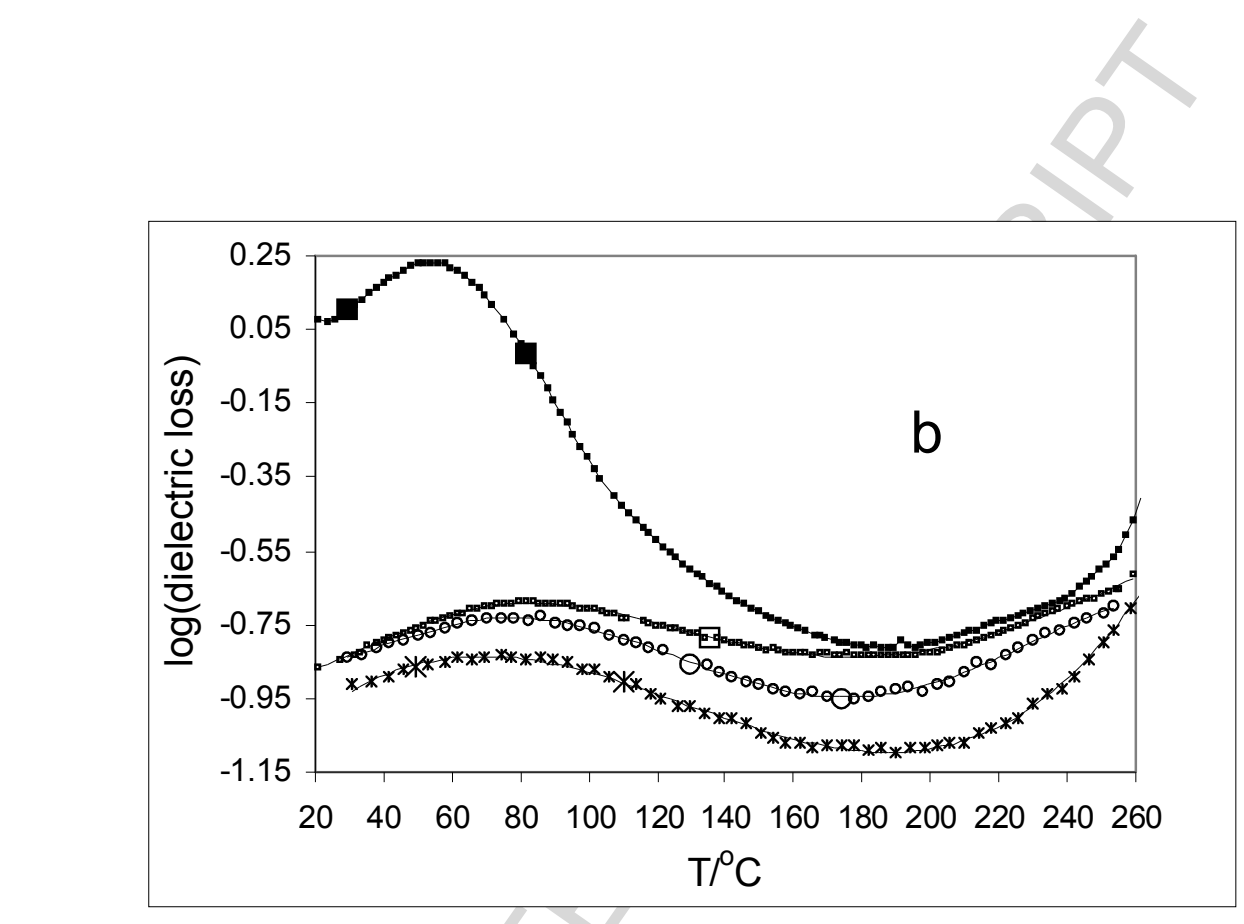

Figure $8 b$ 


\begin{tabular}{|c|c|c|c|c|}
\hline \multirow[t]{2}{*}{$\mathrm{T},{ }^{\mathrm{o}} \mathrm{C}$} & \multicolumn{2}{|c|}{ wet } & \multicolumn{2}{|c|}{ dry } \\
\hline & unmodified & HA-modified & unmodified & HA-modified \\
\hline 200 & $14.0 \pm 0.4$ & $7.4 \pm 0.3$ & $4.0 \pm 0.2$ & $0.50 \pm 0.05$ \\
\hline 230 & $16.4 \pm 0.3$ & $16.1 \pm 0.4$ & $5.7 \pm 0.2$ & $6.0 \pm 0.3$ \\
\hline 260 & $27 \pm 3$ & $25 \pm 4$ & $16.9 \pm 0.3$ & $17.0 \pm 0.5$ \\
\hline
\end{tabular}

Table I 